\title{
Hepatozoon spp. (HEPATOZOIDAE) PREVALENCE IN SNAKES. MORPHOLOGICAL, MORPHOMETRICAL AND MOLECULAR CHARACTERIZATION IN Crotalus durissus terrificus (VIPERIDAE) NATURALLY INFECTED
}

Thesis: T. C. Moço submitted this dissertation for her Masters in General and Applied Biology at Botucatu Biosciences Institute, São Paulo State University, UNESP, Botucatu, São Paulo State, Brazil, 2008.

Advisor: Professor Lucia Helena O’Dwyer de Oliveira

ABSTRACT 1: Prevalence of Hepatozoon spp. infection (Apicomplex, Hepatozoidae) in recently captured Brazilian snakes.

Members of the genus Hepatozoon are the most common intracellular protozoa found in snakes. Since studies about these parasites are very scarce and the importance of this infection in nature and in captivity is a concerning problem, the aim of this study was to determine the prevalence of Hepatozoon spp. infection in snakes from Botucatu region of São Paulo State, Brazil. We investigated 906 recently captured snakes donated to the Center for the Study of Venoms and Venomous Animals (CEVAP) at São Paulo State University (UNESP). Of these animals, 722 (79.7\%) were venomous and 184 (20.3\%) non-venomous. The more common venomous species were Crotalus durissus $(n=556)$, Bothrops jararaca $(n=87)$, and Bothrops pauloensis (Bothrops neuwiedii pauloensis) $(\mathrm{n}=47)$, and non-venomous were Oxyrhopus guibei $(n=49)$, Boa constrictor amarali $(n=42)$ and Waglerophis merremi $(\mathrm{n}=16)$. Blood smears were made from caudal vein blood samples. Hepatozoon spp. infection was detected in 125 snakes (13.8\%). Infection prevalence was respectively $15.1 \%$ and $8.7 \%$ in venomous and non-venomous snakes. The highest infection rates were: $21.8 \%$ in $B$. jararaca, $19.1 \%$ in $B$. constrictor amarali and $15.8 \%$ in C. durissus. Highest infection rates for Hepatozoon spp. were found at Conchas, Itatinga and Pardinho, respectively 47.6\%, 26.7\%, and $17.1 \%$. 
KEY WORDS: Hepatozoon, snakes, prevalence.

ABSTRACT 2: Morfological, morfometrical and molecular characterization of Hepatozoon spp. (Apicomplex, Hepatozoidae) of Crotalus durissus terrificus (Serpentes, Viperidae) naturally infected.

Considering the variety of Hepatozoon parasites infecting Crotalus durissus terrificus and the divergent data in the literature (only two species, H. romani and H. capsulate, are described), the aim of this study was to morphologically, morphometrically and molecularly characterize Hepatozoon spp. from four naturally infected specimens of C. durissus terrificus, and observe changes caused by these protozoa in parasitized erythrocytes. Gamonts, sporogonic stages and red blood cell changes were morphologically and morphometrically analyzed using Qwin Lite 2.5 software. Molecular characterization was performed employing polymerase chain reaction (PCR) and genetic sequencing. Six distinct gamonts were apparently observed and provisionally named gamonts A, B, C, D, E and F. Statistical analysis, however, confirmed the existence of only four parasite populations, which were capable of inducing significant alterations in determined erythrocitic variables. Molecular characterization was unable to differentiate species from the sample fragments studied.

KEY WORDS: Hepatozoon, snakes, morphology, morphometry, molecular characterization.

\section{CORRESPONDENCE TO:}

TATIANA C. MOÇO, Departamento de Parasitologia, Instituto de Biociências, Universidade Estadual Paulista, UNESP, Distrito de Rubião Junior, s/n, 18618-000, Botucatu, SP, Brasil. Email: tati13moco@hotmail.com. 